\title{
O Intelectual como Dirigente e como Educador*
}

\author{
Ana Waleska Pollo Campos Mendonça \\ Pontifícia Universidade Católica do Rio de Janeiro (PUC-Rio)
}

Analisa a concepção de Anísio Teixeira, ao longo dos anos 30, sobre o papel do intelectual no processo de reconstrução da sociedade brasileira. Para Anísio, seria urgente, à época, formar adequadamente $o$ quadro intelectual da nação para que pudesse assumir, plenamente, a função diretiva que the competia nesse processo. Esta função era concebida com um caráter essencialmente educativo, na perspectiva atribuída por Dewey à noção de direção social, o que suporia formar um novo tipo de intelectual, distinto das tradicionais elites brasileiras e cuja marca característica seria a mentalidade científica no seu duplo significado de espírito experimentalista $e$ de espírito democrático. Foi esta concepção do papel do intelectual como dirigente, que não só presidiu à organização da Universidade criada por Anísio em 1935, no Rio de Janeiro (a UDF), como também informou a própria atuação político-administrativa deste educador à frente da Secretaria de Educação do Distrito Federal, de 1932 a 1935.

Nosso trabalho tem como objetivo analisar a concepção de Anísio Teixeira, eminente educador brasileiro, sobre o papel do intelectual no

\footnotetext{
* Este trabalho, extraído de nossa tese de doutorado intitulada Universidade e formação de professores: uma perspectiva integradora - a Universidade de Educação, de Anísio Teixeira, foi apresentado no II Congresso Iberoamericano de História de la Educación Latinoamericana, realizado em Caracas, Venezuela, de 9 a 14 de junho de 1996.
} 
processo de reconstrução da sociedade brasileira, ao longo dos anos 30. oi esta concepção que, sem dúvida, informou sua atuação políticodministrativa à frente da Secretaria de Educação do Rio de Janeiro, de 1932 a 1935, e, particularmente, presidiu à organização da Universidade riada por ele, em 1935 - a Universidade do Distrito Federal (UDF).

Os anos 20 a 40 se constituem um momento extremamente complexo da vida nacional, caracterizado pela crise do sistema oligárquico e pela emergência das massas urbanas, na cena política, como resultado dos processos de industrialização e urbanização, que se aceleram o país. São anos críticos, também, para a história da nossa educação, arcados pela atuação do grupo de intelectuais que se convencionou chamar de Pioneiros da Educação Nova, título que eles mesmos se autotribuíram.

Nosso estudo procura filiar-se a um conjunto de trabalhos que e propõem fazer uma releitura da tradição pedagógica liberal, e em especial do legado dos Pioneiros, objeto, em anos recentes, de uma crítica muitas vezes parcial e demolidora.

Concordamos com a afirmação de Lovisolo (1990) de que, se é preciso que nos voltemos para esta tradição, armados com os instrumentos a crítica teórica e empírica, não se pode simplesmente descartá-la, como e não se constituísse um "solo de reflexão e ação", base para a nossa atuação de educadores, hoje. E desta perspectiva que procuramos nos aproximar do nosso objeto de estudo.

Consideramos que os diferentes projetos educacionais que se defrontaram, nos anos 30, se articulavam a diferentes propostas de reconstrução nacional, no seio das quais a educação, e, especialmente, formação das elites que deveriam dirigir este processo, ocupava uma posiçâo absolutamente central. Resgatar estas concepções nos parece fundamental para se repensar hoje o papel do intelectual na sociedade brasileira e, no bojo desta reflexão, rediscutir o papel da universidade. 


\section{$O$ intelectual como dirigente e educador}

Em maio de 1927, a bordo do navio Pan-América que o conduzia para os Estados Unidos, Anísio registrava no seu diário o balanço que estava a fazer das suas "verdades" em política, em religião e em educação. Sobre o estado atual das suas "verdades" em política, dizia:

A minha crença política definitivamente se inclinou para os regimes descentralizados, facilitadores do florescimento de energias individuais, e das iniciativas pessoais que garantam uma exata classificação social. Regime livre e justo. Livre no sentido de não coibir, de nenhuma sorte, o desenvolvimento do indivíduo e da família, justo no sentido de criar uma atmosfera onde os quadros sociais se instalem com sentido de merecimento e do valor. Justo no sentido de permitir as aristocracias (AT ['Teixeira, A.'], pi 27.04.27/1).' (Grifo do autor).

A seguir, constatava em tom de tristeza:

Estamos longe disto (...).

A nossa democracia tem sido o regime da inversão de valores. Estamos longe de uma fixação honesta dos valores brasileiros. Pelo contrário, o triunfo se está dando pelo melhor dotado de qualidades inferiores que permitem os triunfos culpados de que somos testemunhas.

A América vai mostrar-nos uma democracia descentralizada, com o Estado reduzido ao mínimo e em que um ambiente de cultura intelectual, moral e cívica permitiu a formação de uma aristocracia. Como disse um escritor célebre - a democracia americana encerra uma possibilidade de igualdade, as outras democracias tem procurado obter uma realidade de igualdade (Grifos do autor).

${ }^{1}$ Todos os documentos citados neste artigo, que apresentam na chamada esse tipo de dado bibliográfico, foram recolhidos no Centro de Pesquisa e Documentação em História Contemporânea do Brasil da Fundação Getúlio Vargas, e estão arranjados conforme o Arquivo Lourenço Filho. 
Tanto é justa a primeira, quanto iníqua e revolucionária a segunda.

E essa realidade de igualdade niveladora que cria nas democracias latinas, a abstenção dos melhores, para que se permita o triunfo dos medíocres (AT ['Teixeira, A.'], pi 27.04.27/1).

Ao nosso ver, este trecho expressa uma posição da qual Anísio não veio a afastar-se, em suas linhas gerais, mesmo após a sua estada nos Estados Unidos (e ainda que certos termos - como é o caso de "aristocracia" - tenham sido intencionalmente abandonados).

Segundo nossa perspectiva, na síntese pessoal que o educador elabora, após sua viagem à América do Norte, entre o liberalismo deweyano e a sua formação originária, marcada pela educação jesuítica, este é capaz de integrar a perspectiva meritocratica (fortemente presente na pedagogia jesuíta, de caráter nitidamente elitista), com a sua fé na democracia liberal, que o torna um intransigente defensor do princípio da igualdade de oportunidades educacionais para todos.

No documento manuscrito que parece ser a fundamentação do programa do Partido Socialista, no Distrito Federal ${ }^{2}$ - com cuja proposta de criação Anísio se envolve, juntamente com Hermes Lima - ele viria a afirmar peremptoriamente ser a "mais legítima doutrina democrática" a que propõe, por um lado, "uma ampla e sistemática difusão de cultura e de saber" e , por outro, a "direção pelos mais capazes", e que é característica essencial do regime democrático essa "liderança e governo pelos mais capazes e_esclarecidos" (AT [Teixeira, A.], pi 31/35.00.00/ $6)$.

Para Anísio, entretanto, a "direção intelectual" da sociedade não poderia continuar a ser exercida pelas tradicionais elites letradas

\footnotetext{
${ }^{2}$ A respeito do envolvimento de Anísio com a criação do novo partido, ver a tese de doutorado de Clarice Nunes, especialmente o item 4.2.2 do quarto capítulo, intitulado "Um partido revolucionário" (Nunes, 1991). Há fortes indícios de que Anísio, juntamente com seu amigo e colaborador Hermes Lima, teria se envolvido com a organização de um partido, possivelmente uma dissenção do Partido Autonomista, que iria respaldar a candidatura de Pedro Ernesto à presidência da República, após a promulgação da Constituição de 1934. Esta versão foi confirmada em recente entrevista concedida pelo professor Darcy Ribeiro.
} 
brasileiras, de tal forma distanciadas da realidade concreta que seriam como "os prodígios de circo ou os atletas excepcionais que nos assombram e nos divertem"(idem), mas que nada têm a nos dizer sobre os problemas da vida real.

A necessidade de soluções científicas para os problemas contemporâneos (não só os de caráter estritamente material ou econômico, mas também os problemas de ordem social ou humana, em geral), estaria a exigir não apenas uma nova estratégia de direção da sociedade, mas um novo tipo de dirigente, dotado de "mentalidade moderna esclarecida": o novo intelectual capaz de construir uma cultura adequada à civilização técnica, que a tornasse "consciente, interpretada, formulada em uma filosofia, uma arte, quiçá em uma nova religião" (Teixeira, 1935, p.21), que a humanizasse e lhe abrisse novas sendas, dando assim uma direção ao progresso humano.

Neste sentido, é significativo constatar que os mesmos argumentos utilizados por Anísio para justificar o caráter "científico" das soluções exigidas pela problemática característica das sociedades contemporâneas, servem também para fundamentar a necessidade de se "preparar um Estado novo, capaz de desenvolver as técnicas imprescindíveis ao encaminhamento dos seus problemas atuais" (AT [Teixeira, A.?] pi 31/35.00.00/6, p.3), no documento a que se fez referência anteriormente, que seria a fundamentação para a proposta de criação do Partido Socialista. Aliás, tais argumentos são a base para a organização do novo partido, o que dá claramente a entender que, para Anísio, a disputa pela "direção da sociedade" pressupunha a participação no processo político estrito senso e mesmo a conquista do Estado, ao menos nesse momento especifico da vida nacional (34/35).

Ora, qual seria a estratégia de ação desse novo intelectual para que pudesse efetivamente exercer a direção intelectual (e, mesmo, política) da sociedade?

Essa estratégia, para Anísio, seria uma estratégia necessariamente educativa, até porque, ao incorporar o conceito deweyano de direção, este assumia a idéia de que a direção social supõe 
a formação de uma mentalidade comum, de uma certa identidade de interesses e compreensão, que só seria possível conseguir por meio da educação.

Para Anísio, a direção da sociedade implicaria necessariamente a educação das massas e a formação da opinião pública, de modo a obter uma certa "homogeneidade e coesão", que só podem existir quando "existe uma compreensão comum e um pensamento comum a respeito do homem, do caráter de sua vida econômica, financeira e política, e dos seus problemas de ordem geral" (AT [Teixeira, A.?], pi 31/35.00.00/6, p.6). Esta homogeneidade e coesão seriam necessárias para superar a inevitável resistência e acolher as soluções científicas.

$\mathrm{Na}$ perspectiva de Anísio, a maior racionalidade das ações humanas seria o resultado de um processo de conquista (pois, se o homem é, para ele, sem dúvida, um animal capaz de ser racional, ele só o é raramente, e por conquista). ${ }^{3}$ Daí, o caráter imprescindível de uma ação educativa ampla, intencional e sistemática, que formasse e libertasse a inteligência, sem o que não haveria, para as sociedades modernas, "nem direção e nem sequer salvação" (AT [Teixeira, A.?], pi 31/35.00.00/6, p.6).

E por essa razão que, na fundamentação da proposta de criação do Partido Socialista, Anísio afirmava que

a primeira necessidade de um partido que se propõe incorporar à política nacional todas as conquistas modernas da técnica e da ciência, é a de difundir, por todos os modos e meios, a cultura correspondente a esses últimos progressos humanos.

\footnotetext{
! Na visão progressiva de Anísio, acerca da história da humanidade (a história das sociedades humanas), o dominio da racionalidade seria o estágio mais avançado de um processo através do qual o homem evoluiu de "animal de instinto, a principio", para "animal de hábitos e costumes", determinado pela tradição, e, finalmente, "para animal de pensamento e razão". Este processo, que não teria ocorrido sem enormes dificuldades e resistências, se repetiria na vida pessoal de cada homem. A função da educação seria exatamente a de ajudar o homem a libertar a sua inteligência, tornando-se capaz de dirigir a si mesmo "pelo raciocinio e pela ciência" (AT[Teixeira. A.], pi 31/36.00.00, p.1-11).
} 
A esse plano, diretamente desenvolvido e promovido pelo partido, para a formação, o esclarecimento e a mobilização do pensamento moderno e científico, se seguirá o plano de racionalização das atividades públicas e privadas, não imposto, mas progressivamente desenvolvido por meio da persuasão a que levariam os inquéritos, investigações e julgamento dos competentes (AT [Teixeira, A.?], pi 31/35.00.00/6, p.9).

Parece-nos importante explicitar os diferentes "modos e meios" propostos, neste documento, para a difusão da nova cultura de base científica, a fim de percebermos o alcance abrangente da ação educativa que se pretendia desenvolver junto à sociedade como um todo.

É óbvio que seria preciso, antes de mais nada, garantir "um padrão mínimo da educação para todos" - entendendo-se aí a educação escolar e formal - e uma educação que fornecesse "um mínimo de formação exata e tanto quanto possível científica sobre a vida humana e os negócios da humanidade, especialmente no Brasil" (AT [Teixeira, A.?] pi 31/35.00.00/6, p. 14).

Mas, além disso - o que se constituiria, sem dúvida, uma das principais bandeiras do novo partido - este deveria agir diretamente, "tomando a si a tarefa de preparar e divulgar uma literatura própria, honesta e objetiva, destinada a promover o máximo de esclarecimento público quanto aos problemas brasileiros e suas possíveis soluções", além de garantir uma "rigorosa liberdade de palavra e de imprensa" (AT [Teixeira, A.?] pi 31/35.00.00/6, p.8 e 9).

Com relação a este último aspecto, é interessante destacar a maneira como Anísio justificava uma ardorosa defesa do princípio da liberdade de expressão. Para ele:

Defendendo os processos claros e insofismáveis da argumentação científica, o partido revolucionário não precisava nem de censuras nem de segredo. ${ }^{4}$

\footnotetext{
${ }^{4} \mathrm{O}$ termo "revolucionário" nesse documento aplica-se no sentido de que o novo partido se proporia, entre outras coisas, a resgatar os "verdadeiros" ideais da Revolução de 30.
} 
Nenhum obstáculo seria posto à livre circulação de idéias, a fim de que não casasse a organização partidária com as demais forças que atuam no sentido de fazer predominar os interesses a que os seus grupos se acham ligados.

As idéias deveriam triunfar pelo seu próprio mérito (Grifo meu).

Trata-se, no fundo, de uma atitude tática ${ }^{5}$ de confiança na natureza humana (ou melhor, na razão humana), que levava Anísio a acreditar firmemente que as idéias triunfariam por seus próprios méritos e que o seu livre embate seria a estratégia mais adequada para que as melhores (as mais racionais, sem dúvida) acabassem por se impor.

Ora, para o educador, seria a Universidade a instituição, por excelência, onde se construiria a cultura expressiva das sociedades contemporâneas, de base científica e tecnológica, e onde se formaria o novo intelectual a quem competiria exercer a direção da sociedade. Esta instituição se constituiria, sem dúvida, um dos principais focos de irradiação da nova mentalidade científica que seria preciso difundir, ao máximo, para se conseguir a relativa homogeneidade que viabilizaria o próprio exercício da direção social.

Para Anísio, a Universidade é uma das instituições características e indispensáveis à sociedade moderna, sem a qual não chega sequer a "existir um povo". Para ele:

A função da Universidade é uma função única e exclusiva. Não se trata, somente, de conservar a experiência humana. O livro também as conserva

Trata-se de manter uma atmosfera de saber, para preparar o homem que o serve e desenvolve. Trata-se de conservar o saber vivo e não morto, nos livros ou no empirismo das práticas não intelectualizadas. Trata-se de

\footnotetext{
Este termo é utilizado por Lovisolo (1990) para expressar essa radical confiança de Anísio no homem e na sua racionalidade, que se constituía, para ele, critério orientador da ação, do agir cotidiano - termo, aliás, formulado pelo próprio educador.
} 
formular intelectualmente a experiência humana, sempre renovada, para que a mesma se torne consciente e progressiva (AT [Teixeira, A.?] pi 31/ 35.00.00/6, p.9) (Grifo meu).

É exatamente nessa direção, que a Universidade se constituiria o locus por excelência onde se construiria uma nova cultura, adequada à civilização contemporânea. É por isso que ela deveria ser, antes de mais nada, um centro de investigação e de pesquisa científica. Este caráter, para Anísio, é que a diferenciaria das instituições existentes no país marcadas, nas suas próprias palavras, por um "espantoso praticismo", por um singular utilitarismo, tomado no sentido estreito e limitado do termo.

Importa destacar que a grande crítica que Anísio dirigia às escolas superiores tradicionais não era, propriamente, ao caráter profissionalizante de seus cursos, que ele chegava inclusive a relativizar, acentuando que elas "seriam ainda acadêmicas, tão-somente porque o desaparelhamento substancial, ou a possível ineficiência de métodos para atingir os objetivos profissionais ou utilitários a que se destinavam, as deixavam ao nível das divagações e das generalidades" (Teixeira, 1935, p.23).

O que Anísio criticava dessas escolas era a sua organização fechada e limitada "que substituiu a cultura por duas ou três profissões práticas" (Teixeira, 1962, p. 184-185) e, principalmente, o formalismo reinante no seu interior que as reduzira a meras "instituições emissoras de diplomas honoríficos para ingresso numa das classes privilegiadas do país" (Teixeira, 1935, p.27). Afirmava Anísio:

Profissões se regulamentam, mas não se regulamenta a cultura. Um homem culto e um homem diplomado são duas coisas, infelizmente, bem diversas entre nós (Teixeira, 1962, p. 186).

E por isso que, para este educador, entre as escolas superiores existentes no país e as escolas de que o país necessitaria para formar o 
"seu quadro de intelectuais, de servidores da inteligência e da cultura, de professores, escritores, jornalistas, artistas e políticos", haveria "todo um mundo a transpor" e que, até então, esse quadro se teria "formado ao sabor do mais abandonado e precário autodidatismo" (Teixeira, 1962, p.185).

Estes são exatamente os argumentos de que Anísio se utilizava para justificar a criação da UDF, uma "universidade de fins culturais", que se atreveria a fazer aquilo que aqueles que o deveriam ter feito até agora não o fizeram (referência direta ao governo federal, que procurara obstar a sua criação, especialmente Capanema), que se proporia a exercer nada menos do que a "coordenação intelectual" do país, transformandose num dos seus "grandes centros de irradiação científica, literária e filosófica" (Teixeira, 1962, p. 185-186).

Isto suporia, entretanto, romper com o isolamento que até então caracterizava a vida intelectual do país e, por esta razão, Anísio propunha que a sua Universidade se constituísse, antes de mais nada, um espaço onde o saber fosse construído (e transmitido) de forma socializada, em uma instituição de cultura onde os homens se formassem "num ambiente de livre circulação de idéias, seguindo caminhos diversos, mas em uma mesma atmosfera e um mesmo meio, vivendo, afinal, a vida da inteligência em comum associadamente, fraternalmente" (Teixeira, 1962, p. 183-187). Parade:

A Universidade socializa a cultura, socializando os meios de adquiri-la. A identidade de processos, a identidade de vida e a própria unidade local farão com que nos cultivemos, em sociedade, que ganhemos em comum a cultura, que nos sintamos solidários e unidos pela identidade de objetivos, de preocupações, de interesses e de idéias. E daí que nos sintamos uma comunidade governada por um espírito comum e comuns ideais (Teixeira, 1962, p. 187).

Estes seriam, para Anísio, os procedimentos característicos do verdadeiro espírito universitário, sem os quais não seria possível formar um quadro de intelectuais relativamente coeso, capaz de exercer 
efetivamente a "coordenação da vida espiritual do país"6 (Teixeira, 1962, p. 187). Para este educador, o constitutivo da Universidade estaria, exatamente, na existência, entre os seus integrantes (alunos e professores: "os que sabem e os que desejam aprender"), de uma mentalidade comum, de um "espírito comum", que os animaria nessa tarefa conjunta de "formular intelectualmente a experiência humana, sempre renovada" (Teixeira, 1962, p. 183), e, mais especificamente, de expressar intelectualmente a experiência das sociedades contemporâneas, de base científica e tecnológica, dando-lhe um sentido e uma direção efetivamente humanos.

E por essa razão, ao nosso ver, que Anísio não fala em integração universitária, mas em comunhão em torno dos mesmos ideais e interesses. Este enfoque justificaria, entre outras coisas, o fato de não se prever, na estrutura da UDF, uma unidade institucional que tomasse a si a responsabilidade de articular os diferentes cursos universitários, como é o caso da Faculdade de Filosofia, Ciências e Letras, no projeto original da Universidade de São Paulo (USP), que deveria se constituir o núcleo integrador da universidade, oferecendo os cursos básicos para as diferentes escolas profissionalizantes. Para Anísio, a necessária unidade, no interior da Universidade, não se conseguiria através das estruturas institucionais, mas da comunhão em torno de um mesmo "espírito universitário". E é exatamente esse espírito universitário que ele identificava com a "mentalidade moderna", implicando numa

6 Seria preciso matizar aqui o termo "espiritual", até porque o que Anísio entendia pela "coordenação intelectual" do país tinha, também, uma dimensão explicitamente política. Nessa direção, importa assinalar a semelhança entre os procedimentos propostos para a formação, na universidade, de um quadro de intelectuais que iriam coordenar a "vida espiritual do país" e a formação dos membros do Partido Socialista. A mesma preocupação com a coesão, com a formação de um pensamento comum. de uma compreensão comum, com "uma aprendizagem e ensino comuns" que fizessem de cada um dos membros do partido, quando definitivamente aceito, "um pequeno sacerdote ativo e operante das idéias e soluções do seu partido" (AT [Teixeira, A?] pi 31/350000/6, p.7). Esta seria, na visão de Anísio, a "lição" que as organizações ditas liberais teriam a aprender com os partidos radicais, sejam de extrema esquerda, sejam de extrema direita. 
determinada concepção de ciência (com ênfase na sua base experimental) i especialmente, uma determinada concepção do papel da ciência nas sociedades contemporâneas, que supunha atribuir ao cientista, o intelectual por excelência, uma missão essencialmente educativa.

Esta missão educativa que se expressava na preocupação básica com a socialização do saber científico, por sua vez, se explicitava numa visão específica da relação ensino/pesquisa - que incorporava a idéia do formar escola - e na preocupação com a extensão universitária, entendida na perspectiva da divulgação científica e percebida como uma das funções essenciais da universidade.

\section{Referências bibliográficas}

LOVISOLO, Hugo. Tradição desafortunada: Anísio Teixeira, velhos textos e idéias atuais. In: ALMEIDA, Stela B. (Org.) et al. Chaves para ler Anísio Teixeira. Salvador: OEA/UFBA/EGBA, 1990.

VIENDONÇA, Ana Waleska Pollo Campos. Universidade e formação de professores: uma perspectiva integradora. Rio de Janeiro, 1993. Tese (Doutorado em Educação Brasileira) - PUC-Rio.

NUNES, Clarice. Anísio Teixeira: a poesia na ação. Rio de Janeiro, 1991. 2v. Tese (Doutorado em Educação) - Departamento de Educação, Pontifícia Universidade Católica.

TEIXEIRA, Anísio. Discurso proferido na inauguração dos cursos da UDF, em 31/07/1935. Revista Brasileira de Estudos Pedagógicos, Rio de Janeiro, v.37, n.85, p.181-188, jan./mar. 1962.

. Educação pública: administração e desenvolvimento. Rio de Janeiro: Departamento de Educação, 1935. Relatório do diretor-geral do Departamento de Educação do Distrito Federal. 
efetivamente a "coordenação da vida espiritual do país"6 (Teixeira, 1962, p. 187). Para este educador, o constitutivo da Universidade estaria, exatamente, na existência, entre os seus integrantes (alunos e professores: "os que sabem e os que desejam aprender"), de uma mentalidade comum, de um "espírito comum", que os animaria nessa tarefa conjunta de "formular intelectualmente a experiência humana, sempre renovada" (Teixeira, 1962, p. 183), e, mais especificamente, de expressar intelectualmente a experiência das sociedades contemporâneas, de base científica e tecnológica, dando-lhe um sentido e uma direção efetivamente humanos.

E por essa razão, ao nosso ver, que Anísio não fala em integração universitária, mas em comunhão em torno dos mesmos ideais e interesses. Este enfoque justificaria, entre outras coisas, o fato de não se prever, na estrutura da UDF, uma unidade institucional que tomasse a si a responsabilidade de articular os diferentes cursos universitários, como é o caso da Faculdade de Filosofia, Ciências e Letras, no projeto original da Universidade de São Paulo (USP), que deveria se constituir o núcleo integrador da universidade, oferecendo os cursos básicos para as diferentes escolas profissionalizantes. Para Anísio, a necessária unidade, no interior da Universidade, não se conseguiria através das estruturas institucionais, mas da comunhão em torno de um mesmo "espírito universitário". E é exatamente esse espírito universitário que ele identificava com a "mentalidade moderna", implicando numa

\footnotetext{
" Seria preciso matizar aqui o termo "espiritual", até porque o que Anísio entendia pela "coordenação intelectual" do país tinha, também, uma dimensão explicitamente política. Nessa direção, importa assinalar a semelhança entre os procedimentos propostos para a formação, na universidade, de um quadro de intelectuais que iriam coordenar a "vida espiritual do país" e a formação dos membros do Partido Socialista. A mesma preocupação com a coesão, com a formação de um pensamento comum, de uma compreensão comum, com "uma aprendizagem e ensino comuns" que fizessem de cada um dos membros do partido, quando definitivamente aceito, "um pequeno sacerdote ativo e operante das idéias e soluções do seu partido" (AT [Teixeira, A?] pi 31/350000/6, p.7). Esta seria, na visão de Anísio, a "lição" que as organizações ditas liberais teriam a aprender com os partidos radicais, sejam de extrema esquerda, sejam de extrema direita.
} 
determinada concepção de ciência (com ênfase na sua base experimental) 1 especialmente, uma determinada concepção do papel da ciência nas sociedades contemporâneas, que supunha atribuir ao cientista, o intelectual por excelência, uma missão essencialmente educativa.

Esta missão educativa que se expressava na preocupação básica com a socialização do saber científico, por sua vez, se explicitava numa visão específica da relação ensino/pesquisa - que incorporava a idéia do formar escola - e na preocupação com a extensão universitária, entendida na perspectiva da divulgação científica e percebida como uma das funções essenciais da universidade.

\section{Referências bibliográficas}

LOVISOLO, Hugo. Tradição desafortunada: Anísio Teixeira, velhos textos e idéias atuais. In: ALMEIDA, Stela B. (Org.) et al. Chaves para ler Anísio Teixeira. Salvador: OEA/UFBA/EGBA, 1990.

MENDONÇA, Ana Waleska Pollo Campos. Universidade e formação de professores: uma perspectiva integradora. Rio de Janeiro, 1993. Tese (Doutorado em Educação Brasileira) - PUC-Rio.

NUNES, Clarice. Anísio Teixeira: a poesia na ação. Rio de Janeiro, 1991. 2v. Tese (Doutorado em Educação) - Departamento de Educação, Pontifícia Universidade Católica.

TEIXEIRA, Anísio. Discurso proferido na inauguração dos cursos da UDF, em 31/07/1935. Revista Brasileira de Estudos Pedagógicos, Rio de Janeiro, v.37, n.85, p.181-188, jan./mar. 1962.

. Educação pública: administração e desenvolvimento. Rio de Janeiro: Departamento de Educação, 1935. Relatório do diretor-geral do Departamento de Educação do Distrito Federal. 
Recebido em 16 de julho de 1996.

Ana Waleska P. C. Mendonça, doutora em Educação Brasileira pela Pontifícia Universidade Católica do Rio de Janeiro (PUC-Rio), é, no momento, diretora e professora associada do Departamento de Educação dessa universidade.

The aim of this paper is to analyze Anísio Teixeira 's conception of the role of intellectuals in the process of reconstruction of the Brazilian Society during the 30 's. According to Anísio, it would be important to prepare a nation's intellectual personnel capable of assuming its directive role. This role was considered as being essentially educative, according to the conception attributed by Dewey to the notion of social directiveness. This would presuppose a new kind of intellectual, different from the Brazilian traditional elite and characterized by a scientific mentality composed by a experimental spirit and a democratic spirit. The above mentioned conception of the role of intellectual as a conductor shaped both the organization of the University created by Anisio at Rio de Janeiro (the UDF) and his own behavior as the head of the Educational Authority of Rio de Janeiro during the period 1932-1935.

Le but de notre travail est d'analyser la conception d'Anísio Teixeira, tout au long des années 30, sur le rôle de l'intellectuel au cours du procès de reconstruction nationale de la société brésilienne. Pour Anísio, il était urgent, à cette époque-là, déformer adéquament le cadre intellectuel de la nation pour qu 'il puisse exercer pleinement la fonction directive qui lui appartennait. Cette fonction était conçue comme une fonction essentiellement éducative, dans le sens de ce que Dewey appelait la direction sociale. Cela supposait former un nouveau type d'intellectuel, qui se distinguait des élites traditionnelles brésiliennes dont la marque serait la mentalité scientifique, dans le double sens 
$d$ esprit d'expérimentation et d'esprit démocratique. Cette conception $d u$ role de l'intellectuel, autant que dirigeant, est à l'origine non seulement de l'organization de l'Université créée par Anísio en 1935, au Rio de Janeiro (l'UDF), mais aussi de l'action politique et administrative de cet éducateur à la tête du Bureau de l'Education du Distrito Fédéral, de 1932 à 1935.

Nuestro trabajo tiene por objetivo analisar la concepción de Anísio Teixeira, a Io largo de los años 30, acerca del papel del intelectual en el proceso de reconstrucción nacional de Ia sociedad brasileña. Para Anísio, era urgente, por aquél entonces, formar adecuadamente a los cuadros intelectuales de la Nación para que ellos pudieran ejercer plenamente la función directiva que les competia. Esta función era concebida con un carácter fundamentalmente educativo, en el sentido que le atribuyó Dewey, de dirección social, lo que supondría formar un nuevo tipo de intelectual distinto de Ias elites tradicionales brasileñas, y cuya característica sería la mentalidad científica, en su doble significado de espíritu experimentalista y de espíritu democrático. Fue esta concepción del papel del intelectual como dirigente, que no sólo presidió a la organización de la Universidad creada por Anísio en 1935, en Rio de Janeiro (UDF), como también informó la propia actuación político-administrativa de este educador al frente de la Secretaría de Educación del Distrito Federal, de 1932 a 1935. 